\title{
Research Paper: The Effect of Through-Range Versus Shortened-Length Exercise Training on Upper Quarter Posture Among Students With Forward Head Posture: A Randomized Clinical Trial
}

\author{
Parisa Sayyadi $^{1}$ Q , Rahman Sheikhhoseini ${ }^{*}$ Q, Kieran O'Sullivan $^{2,3}$ Q, Ramin Balouchi ${ }^{1}$
}

1. Department of Corrective Exercises \& Sport Injury, Faculty of Physical Education and Sport Sciences, Allameh Tabataba'i University, Tehran, Iran 2. Ageing Research Centre, Health Research Institute, University of Limerick, Limerick, Ireland.

3. School of Allied Health, University of Limerick, Limerick, Ireland.

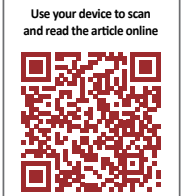

Citation: Sayyadi P, Sheikhhoseini R, O'Sullivan K, Balouchi R. The Effect of Through-Range Versus Shortened-Length Exercise Training on Upper Quarter Posture Among Students With Forward Head Posture: A Randomized Clinical Trial. Journal of Modern Rehabilitation. 2019; 13(1):49-58. http://dx.doi.org/10.32598/JMR.13.1.49

http://dx.doi.org/10.32598/JMR.13.1.49

Article info:

Received: 13 May 2018

Accepted: 04 Sep 2018

Available Online: 01 Jan 2019

Keywords:

Exercise therapy, Posture, Head, Kyphosis, Shoulder

\section{ABSTRACT}

Introduction: The purpose of this study was to investigate the effects of shortened-length versus through-range exercise training on upper quarter posture in primary school students with Forward Head Posture (FHP).

Materials and Methods: Sixty pain-free participants with FHP were randomly allocated to one of three groups; shortened-length training $(n=20)$, through-range training $(n=20)$, and notreatment control group $(n=20)$. The shortened-length and through-range groups participated in training programs 3 times per week for 8 weeks. Upper quarter postures, including Craniovertebral Angle (CVA), Shoulder Angle (SA), Cranial Angle (CA), and thoracic kyphosis were measured by photogrammetry before and after the training. The confidence level was set at $95 \%(\mathrm{P}<0.05)$.

Results: After training, both exercise groups showed significant changes in $\mathrm{CVA}(\mathrm{P}=0.001)$ $\mathrm{SA}(\mathrm{P}=0.001), \mathrm{CA}(\mathrm{P}=0.001)$, and thoracic kyphosis $(\mathrm{P}=0.001)$ compared to the control group. Furthermore, CVA changed more in the shortened-length exercise group compared to the through-range exercise group $(\mathrm{P}=0.003)$ (effect size $=0.446$ ).

Conclusion: Both through-range and shortened-length exercises altered upper quarter alignment. The shortened-length training resulted in a larger change in CVA. These changes were small, and more studies are needed to investigate the effects of such training programs among people with pain.

\section{* Corresponding Author:}

Rahman Sheikhhoseini, PhD.

Address: Department of Corrective Exercises \& Sport Injury, Faculty of Physical Education and Sport Sciences, Allameh Tabataba'i University, Tehran, Iran. Tel: +98 (918) 8668284

E-mail: rahman.pt82@gmail.com 


\section{Introduction}

\section{I}

n Forward Head Posture (FHP), the head is located forward relative to the vertical line of gravity, which may result in increased cervical lordosis and positional changes in the craniocervical region $[1,2]$.

Poor school ergonomics is one of several risk factors implicated in developing FHP $[3,4]$.

FHP and rounded shoulders are common postural presentations in all age groups, children, and adolescents alike. Since spinal and neck pain is common in adolescents, researchers propose an association between FHP and spinal pain [5]. However, a clear relationship between postural alignment and musculoskeletal pain in adolescent students has not yet been demonstrated [6]. Since adolescents with FHP show different muscular functions in the cervical region, and altered breathing patterns [7-10]. managing FHP by health professionals may benefit musculoskeletal disorders.

Several interventions are proposed to manage FHP, including taping, manipulation, electrotherapy, and joint mobilization [11-14]. A commonly advocated approach is exercise that stretches the upper trapezius, sternocleidomastoid, and levator scapula muscles, and strengthens deep cervical flexors [15-18]. A recent meta-analysis showed high heterogeneity in the results of randomized controlled trials examining the effects of different exercise regimens to manage FHP [19]. Therefore, additional research is needed to evaluate if some exercise programs are more effective for FHP.

It has been proposed that muscle fibers demonstrate different mechanical behaviors when they are weakened in the shortened rather than elongated form. The muscles that have been weakened in the long length show more weakness in their shortened length, while it may not demonstrate any dysfunction in other lengths of muscle fibers [20]. Since some muscles may be weakened in the elongated length in persons with FHP, and they are predisposed to malfunction in their short length, it seems rational to design some exercise to strengthen these muscles in the shortened length [20,21].

Although many studies have investigated the effect of different exercises (through range exercises) on subjects with FHP, no research has studied the effects of strengthening exercises in shortened length positions of these subjects [19]. Therefore, we designed the shortenedlength exercises to emphasis on muscle strengthening while muscle overloading was performed in muscle shortened length. For this purpose, the subjects were asked to move the target muscles to the maximal possible shortened length and hold it for 5 seconds while they try to push the distal segments to reach a more shortened length by frequency of one effort per second (five efforts in each movement).

To our knowledge, the effect of training in the shortened muscle length on FHP in children has not been examined so far. Therefore, the purpose of this study was to examine the impact of through-range versus shortenedlength exercise training on pain-free adolescent students with FHP.

\section{Materials and Methods}

\section{Study participants}

In this randomized clinical trial, 60 male pain-free volunteer students with FHP were recruited and randomly assigned into one of three groups of 20 people; shortened-length, through- range, and control group. According to the research objectives and similar previous study, the sample size was estimated as 15 subjects for each group by using $\mathrm{G} \times$ Power software V. 3.1 considering $\alpha=0.05$ and power of $80 \%$ and based on the Craniovertebral Angle (CVA) in the corrective exercise group [16, 22]. To compensate the possible dropouts, 20 subjects were selected for each group.

\section{Inclusion and exclusion criteria}

The students were included in this study if they were pain-free, 7 to 13 years old, with CVA less than 50 degrees (as a diagnosis of FHP, based on previous studies) $[13,23,24]$. The students were excluded from the study if they had a history of heart disease or other illnesses that could interfere with research, obvious scoliosis and structural hyperkyphosis (non-correction by performing stretching exercises) according to New York criteria, and history of any medical conditions that could interfere with the study [25]. The subjects who had a history of exercise in professional and regular sports programs were also excluded.

\section{Study procedure}

After selecting the subjects, an introduction session was held for the subjects, and their demographic data were obtained. The study process and objectives were explained to the subjects, and informed consent was obtained from their parents. Only general information about the intervention was provided to the subjects, and 
their parents and subjects in two intervention groups were blinded to group allocation.

The subjects were assured that the obtained data would remain confidential, and they could leave the research whenever they wanted. At the beginning of the study, the study variables were recorded by a blinded examiner who also performed posttest. After the pretest, the subjects of two intervention groups attended to that training program that was under direct supervision of an expert trainer (who was blinded to the study objectives) three sessions per week for eight weeks. The posttest was done five and eight weeks after the beginning of exercise training. The subjects in the control group were asked not to participate in any other exercise during the study. The subjects of the control group were allowed to willingly participate in the same exercise program after the study ending under direct supervision of the first author.

\section{Exercise programs}

Before starting the main exercise, the subjects were asked to do a 10-min warm-up by stretching, jogging, and running. After that, the main exercise program consisted of five stretching exercises followed by 4 strengthening exercises. For stretching exercises, the subjects were asked to perform the stretches until feeling pain or discomfort and held the position for 30 seconds in two sets [26]. These stretching exercises were performed before starting the strengthening exercises and were done in the same manner in both through-range and shortened-length groups. The strengthening exercises were done in two sets of 8-12 repetitions in both intervention groups

In the through-range exercise group, the strengthening exercises started from the beginning of the range and continued slowly until the end of the range. Then, without stopping, it returned into its original state, and this cycle was repeated for 8-12 times in each movement. However, in the shortened-length exercise group, the subjects were asked to move the weight to the maximal possible shortened length of the target muscles and hold it for five seconds while they tried to push the distal segments to reach more shortened length by frequency of one effort per second (five efforts in each movement).

Then the subjects were asked to release the position and return to the beginning of the range. This cycle was repeated 8-12 times for each strengthening exercise in the shortened-length training group. After performing the exercise programs, both groups performed ten minutes of cool down by general stretching and walking.
In both experimental groups, the first two weeks were considered as an introduction to the program. Afterward, for each strengthening exercises, the 1RM (one-repetition maximum) was measured using the reliable and validated Brzycki formula [27]. The progressive exercises were applied from the third week. The strengthening exercises were prescribed at an exercise intensity of $35 \%$ of measured 1RM by using free weights. After three weeks, 1RM was measured again, and exercises were applied at an intensity of $50 \%$ of the 1RM by using free weights on the distal part of the moving segments. The exercise program consisted of nine exercises as follows that were adopted from Ruivo et al. program [15].

\section{Stretching exercises:}

Pectoral minor stretching in standing position: the subjects were asked to stand in the door and stabilize the forearm with door pillar and then rotate the trunk to the opposite direction. This action leads to shoulder external rotation in the involved arm and then the exercise was done on the other side.

Sternocleidomastoid muscles stretching in standing position: the starting position was standing with optimal posture and place the right arm behind the body, lowering the shoulder. The subjects were asked to perform abdominal bracing and chin tuck, then perform contralateral cervical side bending concurrent with rotation to the same side of right hand. They allowed using left hand to apply additional pressure on the movement, too. This exercise was also performed on the other side.

Levator scapulae stretching in standing position: the starting position was standing with optimal posture and place the right arm behind the body, lowering the shoulder. The subjects were asked to perform abdominal bracing and chin tuck, then perform cervical side bending concurrent with rotation to the contralateral side of right hand. They allowed using left hand to apply additional pressure on the movement, too. This exercise was also performed on the other side.

Quadruped thorax stretching exercise: the aim was to stretch pectoral muscles and mobilize the thoracic spine into extension. The subjects were asked to come down onto the floor on all fours, making sure knees are under hips with shins placed firmly on the ground, the hands placed directly under shoulders with fingers spaced widely apart and facing forward. Before starting the stretch, a deep breath was taken and then drawn the abdomen toward thighs. Then the subjects were asked to 
move their body caudally until they felt stretching in the mentioned structures without pain sensation.

Chin tuck in the supine position: the main goal was to stretch suboccipital muscles and gently activate longus colli and longus capitis muscles and then activate and train the deep cervical flexors. The subjects were in a supine position with a head in contact with the floor. Then they were instructed to perform chin tuck by drawing the chin toward the sternal notch without elevating the head from the floor.

\section{Strengthening exercises}

Shoulder external rotation in side-lying: the goal was to activate teres minor and infraspinatus muscles. The starting position was side-lying on the right hand and left armrest on the lateral chest wall, fully internal rotation, and elbow in $90^{\circ}$ of flexion. The subjects were asked to rotate the shoulder externally. Free weights were added to the wrist when applicable. This exercise was performed bilaterally, too.

Arm horizontal abduction with external shoulder rotation in prone position: the main goal was to activate middle trapezius, lower trapezius, rhomboids, infraspinatus, and teres minor muscles. The starting position was prone lying with bilateral arm $90^{\circ}$ abduction and full external rotation, elbow full extension, and chin tuck. The subjects were instructed to abduct the arms horizontally toward the ceiling. Free weights were added to both wrists when applicable.

$\mathrm{Y}$ to $\mathrm{I}$ in the prone position: the aim was to activate middle trapezius, lower trapezius, and serratus anterior muscles. The starting position was lying in the prone position with $90^{\circ}$ bilateral shoulder abduction and full external rotation ("Y" position). Then the subjects were instructed to move both arms into a position of full bilateral elevation with the elbow extension forming an "I". Free weights were added to the bilateral wrist when applicable.

W exercise: the main goal was to activate middle trapezius, lower trapezius, rhomboids, infraspinatus, and teres minor muscles. The starting position was prone lying with $90^{\circ}$ abduction bilateral of the arm and full external rotation, elbow $90^{\circ}$ of flexion, and chin tuck. The subjects were instructed to abduct the arms horizontally toward the ceiling. Free weights were added to the bilateral wrist when applicable.

Postural assessment
CVA, Cranial Angle (CA), and Shoulder Angle (SA) were measured by the photogrammetric method. The previous study showed high reliability of measurement for upper body posture in this method [23]. Before assessment, special black markers (a circle sticker with diameter of $14 \mathrm{~mm}$ ) were attached to the bony landmarks on C7, acromion, eye tragus, and ear tragus. Then the subjects were asked to stand quietly and look at a point on the wall upfront. A digital camera (Canon Inc. model EOS 750D) was set at a distance of $80 \mathrm{~cm}$ from standing point, and the $\mathrm{C} 7$ height of every subject [24].

Then a photo was taken from lateral view. After that, the subjects were asked to leave the position and walk slowly in the laboratory for two minutes. Then another photo was taken in the same manner, and this process was repeated. Afterward, postural measurements were extracted from these three photos by using AutoCAD software (AutoCAD V. 20.1) and the mean value was considered as the study data for analysis. The CVA was obtained from the angle between the horizontal line that passes through the $\mathrm{C} 7$ spine and the line that connects $\mathrm{C} 7$ to the ear tragus. To measure the SA, the angle between the line that connects the $\mathrm{C} 7$ to the midpoint of the arm and the horizontal line passing through the midpoint of the arm was measured. For the CA, the angle between the line that connects the ear tragus to the eye tragus and the horizontal line passing through the midpoint of the ear tragus was obtained [18]

Based on a previous study, a $50 \mathrm{~cm}$ long, $2 \mathrm{~cm}$ wide flexible ruler was used to measure the thoracic kyphosis angle [16]. Firstly, the spinous processes of T2 and T12 were identified and marked with blue board marker as bony landmarks to measure thoracic kyphosis. The subjects were asked to stand upright barefoot on a flat surface, distribute body weight equally on both feet with the distance of shoulders width, and gaze at a point on the front wall. Then the subjects were instructed to wait for one minute in this position to reach normal posture.

After that, the sternum and symphysis pubis were stabilized by two dowels horizontally mounted on the spine stabilizer instrument to minimize postural sway. Then the flexible ruler was molded on the thoracic curve, and the points adjacent to $\mathrm{T} 2$ and $\mathrm{T} 12$ spinous processes (that marked previously on the spine) were marked on the ruler. The flexible curve was then marked on the white paper sheets carefully.

The T2 and T12 position points were marked, too. This procedure was performed three times with 1-min interval, and the mean value of three trials was considered as 


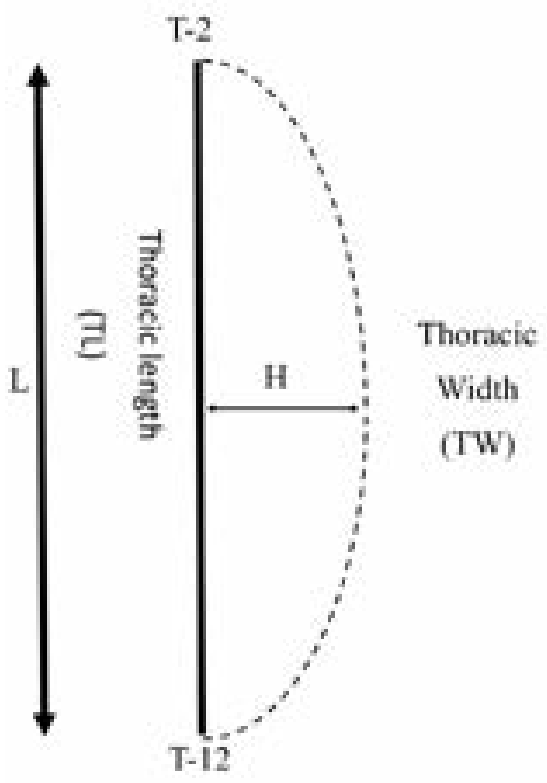

$J M R$

Figure 1. Method of the depiction of $\mathrm{L}$ and $\mathrm{H}$ lines by using a flexible ruler for measurement of thoracic kyphosis

a kyphosis angle [16]. After that, quantification of thoracic kyphosis angle was performed by identifying the " $\mathrm{H}$ " and " $\mathrm{L}$ " distances and inserting in the equation of "4[Arctan(2H/L)]", as described by previous studies [16, 28]. The validity and reliability of this method have been already demonstrated (Figure 1) [28].

\section{Statistical analyses}

All analyses were conducted in SPSS V. 20. The Shapiro-Wilk test assessed the normality of data. Descriptive statistics were used to describe the data. One-way ANOVA was run to assess baseline between-group differences. Two-way repeated measure ANOVA was used to examine the effect of time and group on postural measures. One-way ANCOVA was conducted to compare the effectiveness of the two exercise training programs while controlling for baseline postural measures.

The confidence level was considered to be $95 \%$ $(\mathrm{P}<0.05)$. The power of analyses and effect size (Partial Eta Squared) was calculated for each variable, too. The effect size was categorized as small $(\mathrm{d}=0.2)$, medium $(d=0.5)$, and large $(d \geq 0.8)$ [29]. The plots of the means of three groups were drawn to interpret the findings of two-way repeated measure ANOVA.

\section{Results}

Table 1 presents the demographic data of all groups, and one-way ANOVA results did not show any statistically significant differences between groups.

Two-way ANOVA demonstrated a statistically significant interaction of group and time on CVA $\left(\mathrm{F}_{2,54}=22.92\right.$, $\mathrm{P}=0.001), \mathrm{CA}\left(\mathrm{F}_{2,54}=8.32, \mathrm{P}=0.001\right), \mathrm{SA}\left(\mathrm{F}_{2,54}=26.20\right.$, $\mathrm{P}=0.001)$ and thoracic kyphosis $\left(\mathrm{F}_{2,54}=6.55, \mathrm{P}=0.001\right)$ (Table 2). The mean values of CVA, CA, SA, and thoracic kyphosis of each "group" and "time" illustrate that the path of progression in two experimental groups differs from the control group (Figure 2).

Therefore, one-way ANCOVA was conducted to compare the effectiveness of two exercise programs while controlling for pretest values in all study parameters. There was only a significant difference in mean CVA in week $5\left(\mathrm{~F}_{1,38}=10.15, \mathrm{P}=0.003\right)$ and week $8\left(\mathrm{~F}_{1,38}=9.84\right.$, $\mathrm{P}=0.003$ ) between the two exercise groups (Table 3). Comparing the estimated marginal means showed that the postural change was greater in the shortened-length training group (week five: 49.14 degrees, week eight: 51.15 degrees) compared to the through-range training group (week five: 47.51 degrees, week eight: $49.21 \mathrm{de}-$ grees). The effect size of these differences between the exercise groups were small ( 0.201 and 0.215$)$.

\section{Discussion}

Table 1. Comparison of participants' demographic characteristics before the study using one-way ANOVA

\begin{tabular}{ccccc}
\hline Variable & & Mean \pm SD & Control & P \\
\cline { 1 - 3 } Group & Shortened-Length & Through-Range & $10.75 \pm 0.85$ & 0.409 \\
\hline Age $(\mathrm{y})$ & $11.05 \pm 0.75$ & $11.05 \pm 0.82$ & $144.75 \pm 7.51$ & 0.562 \\
Height $(\mathrm{cm})$ & $147.45 \pm 6.5$ & $145.05 \pm 7.2$ & $38.70 \pm 8.56$ & 0.162 \\
Weight $(\mathrm{kg})$ & $39.80 \pm 10.41$ & $41.85 \pm 12.6$ & $18.41 \pm 1.89$ & 0.431 \\
\hline BMI $(\mathrm{kg} / \mathrm{m} 2)$ & $17.9 \pm 2.32$ & $19.90 \pm 3.91$ & & \\
\hline
\end{tabular}

SD: Standard Deviation; BMI: Body Mass Index 
Table 2. Comparing upper quarter postural measures in the three study groups

\begin{tabular}{|c|c|c|c|c|c|c|c|c|}
\hline \multirow[b]{2}{*}{ Variable } & \multirow[b]{2}{*}{ Time } & \multicolumn{3}{|c|}{ Mean $\pm S D$} & \multirow[b]{2}{*}{$F_{(2,54)}$} & \multirow{2}{*}{$\begin{array}{c}\text { P } \\
\text { (TimexGroup } \\
\text { Interaction) }\end{array}$} & \multirow{2}{*}{$\begin{array}{l}\text { Power of } \\
\text { Analyses }\end{array}$} & \multirow{2}{*}{$\begin{array}{l}\text { Effect } \\
\text { Size }\end{array}$} \\
\hline & & $\begin{array}{l}\text { Shortened- } \\
\text { Length }\end{array}$ & $\begin{array}{l}\text { Through- } \\
\text { Range }\end{array}$ & Control & & & & \\
\hline \multirow{3}{*}{ CVA } & $\begin{array}{l}\text { Before the } \\
\text { Intervention }\end{array}$ & $45.80 \pm 4.10$ & $44.68 \pm 3.88$ & $47.08 \pm 2.76$ & \multirow{3}{*}{22.915} & \multirow{3}{*}{$0.001^{\star}$} & \multirow{3}{*}{1.00} & \multirow{3}{*}{0.446} \\
\hline & $\begin{array}{l}\text { Five weeks after } \\
\text { the intervention }\end{array}$ & $49.74 \pm 4.83$ & $46.92 \pm 4.16$ & $47.73 \pm 2.87$ & & & & \\
\hline & $\begin{array}{l}\text { Eight weeks } \\
\text { after the inter- } \\
\text { vention }\end{array}$ & $51.73 \pm 5.06$ & $48.59 \pm 4.48$ & $48.07 \pm 3.25$ & & & & \\
\hline \multirow{3}{*}{ SA } & $\begin{array}{l}\text { Before the } \\
\text { Intervention }\end{array}$ & $53.17 \pm 8.80$ & $51.48 \pm 8.06$ & $57.17 \pm 5.45$ & \multirow{3}{*}{26.20} & \multirow{3}{*}{$0.001^{\star}$} & \multirow{3}{*}{1.00} & \multirow{3}{*}{0.479} \\
\hline & $\begin{array}{l}\text { Five weeks after } \\
\text { the intervention }\end{array}$ & $57.05 \pm 7.64$ & $54.06 \pm 7.94$ & $56.60 \pm 6.77$ & & & & \\
\hline & $\begin{array}{l}\text { Eight weeks } \\
\text { after the inter- } \\
\text { vention }\end{array}$ & $59.57 \pm 7.36$ & $56.50 \pm 8.16$ & $56.37 \pm 6.54$ & & & & \\
\hline \multirow{3}{*}{ Kyphosis } & $\begin{array}{l}\text { Before the } \\
\text { Intervention }\end{array}$ & $36.94 \pm 7.20$ & $37.05 \pm 7.21$ & $39.18 \pm 5.69$ & \multirow{3}{*}{5.55} & \multirow{3}{*}{$0.001^{\star}$} & \multirow{3}{*}{0.974} & \multirow{3}{*}{0.163} \\
\hline & $\begin{array}{l}\text { Five weeks after } \\
\text { the intervention }\end{array}$ & $34.52 \pm 7.27$ & $34.97 \pm 7.10$ & $38.82 \pm 6.80$ & & & & \\
\hline & $\begin{array}{l}\text { Eight weeks } \\
\text { after the inter- } \\
\text { vention }\end{array}$ & $32.42 \pm 7.61$ & $32.05 \pm 7.18$ & $38.11 \pm 6.47$ & & & & \\
\hline \multirow{3}{*}{ CA } & $\begin{array}{l}\text { Before the } \\
\text { Intervention }\end{array}$ & $26.44 \pm 4.37$ & $23.99 \pm 6.44$ & $22.48 \pm 4.04$ & \multirow{3}{*}{8.318} & \multirow{3}{*}{$0.001^{\star}$} & \multirow{3}{*}{0.988} & \multirow{3}{*}{0.226} \\
\hline & $\begin{array}{l}\text { Five weeks after } \\
\text { the intervention }\end{array}$ & $23.90 \pm 4.07$ & $21.84 \pm 5.70$ & $22.05 \pm 4.80$ & & & & \\
\hline & After 8 weeks & $21.07 \pm 4.57$ & $19.49 \pm 5.45$ & $21.44 \pm 6.33$ & & & & \\
\hline
\end{tabular}

*Statistically significant differences were observed

CVA: Craniovertebral Angle; SA: Shoulder Angle; CA: Cranial Angle

The results of this study demonstrated that upper quarter alignment altered significantly in both exercise groups, but CVA showed more changes in the shortenedlength group. This clinical trial indicates that postural corrections, especially for FHP (i.e. thoracic kyphosis, and rounded shoulders), are possible with corrective exercise programs. The results provide preliminary evidence that shortened-length training might be slightly more effective for CVA, too. This is consistent with other study results reporting that corrective exercises can alter upper body posture [19, 30-32].

Also, a recent meta-analysis finding support corrective exercises to promote upper body posture in subjects with FHP (the level of evidence of 1a for CVA) [19]. Based on our findings, CVA and SA changed moderately (moderate effect sizes) in both exercise groups, whereas changes in kyphosis and CA were small. The current results are inconsistent with a meta-analysis that showed the CVA might respond more to corrective exercise programs [19].

Changing posture in the exercise groups compared to the control group may be due to the restoration of agonistic/antagonistic muscular balances by increasing the elongation capacity of shortened muscles and strengthening of the weak ones [33]. In this study, the active stretching exercises of levator scapulae, sternocleidomastoid, and pectoral muscles in addition to strengthening of the rhomboid, lower and middle trapezius and shoulder rotator cuff muscles were prescribed to achieve such a desired postural alignment $[15,24]$

To our knowledge, this is the first study examining the effects of shortened-length training exercises to correct postural malalignments. Our findings support that shortened-length training may be slightly more effective for correcting decreased CVA in subjects with FHP in 

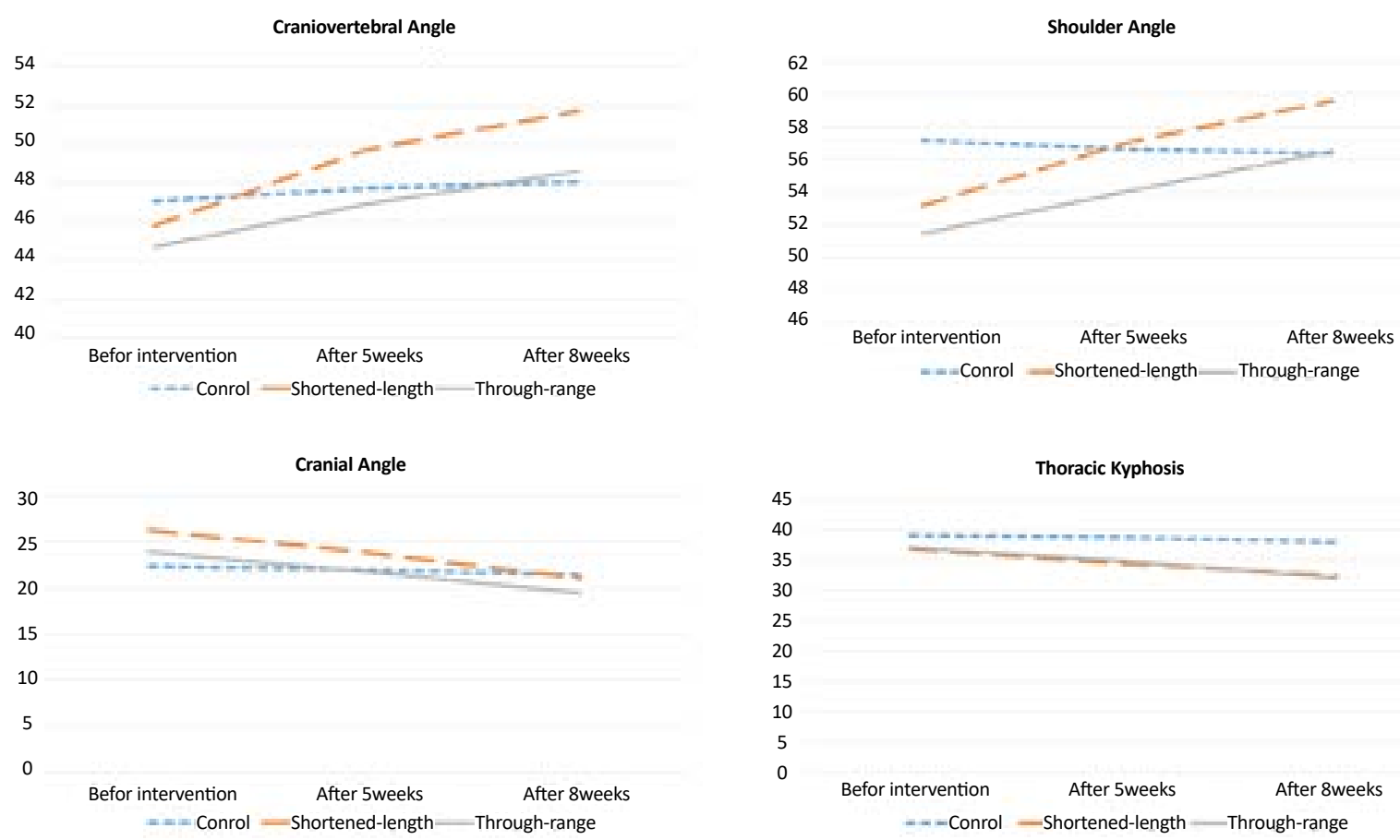

$J \mathrm{MR}$

Figure 2. Mean values of Craniovertebral Angle (CVA), Cranial Angle (CA), Shoulder Angle (SA) and thoracic kyphosis of three groups (shortened-length, through-range, and control) and assessment times (before the intervention, five and eight weeks after the intervention)

comparison with through-range training, but this difference was small based on small effect size. This finding suggests that weakened muscles in the FHP may be in elongated length at rest, so these muscles display weakness when they place in their shortened length rather than other muscle lengths.

The excessive actin to myosin filaments overlap is proposed as an explanation of the underlying mechanism of slightly more effectiveness of shortened-length training protocol $[20,34]$. Considering specific adaptation to imposed demands principle, it seems rational to develop exercise programs to train the weakened muscles in the shortened length, which demonstrated more weakness [35]. This technic may be more effective in restoring their function/balance and be more effective in correcting postural malalignment.

Though the shortened-length training was more effective in correcting CVA, both exercise groups had a similar effect on thoracic kyphosis, CA and SA. This finding may be explained by the primary focus of this study on the impact of shortened-length training in subjects with FHP. Therefore, the exercise programs were designed to address FHP rather than thoracic kyphosis or SA. In this regard, we need more tailored exercise programs to assess their effect on thoracic hyperkyphosis and rounded shoulder postures. Secondly, the lack of additional benefit from shortened-length training for CA compared with through-range ones may explain why CA responds less to exercise than CVA, as illustrated by the smaller effect size of CA (0.226) than CVA (0.446) achieved in this study [19].

Previous studies suggest that long-time attendance at school may predispose students to several changes in their lifestyle and habits that may result in their muscle changes $[36,37]$. Thus health professionals and parents should pay more attention to prevent these problems. According to the results, the exercise program helps change postural parameters as it is more evident for CVA and $\mathrm{SA}$, so prescribing corrective exercises are suggested for primary school students. Also, this effect may be slightly better for CVA using shortened-length exercise training.

While the findings may be useful in designing the corrective exercise protocols, we need further investigation to establish the relationship between posture and pain, and its implications for rehabilitation. This is particularly important considering the wide range of factors other than posture, which have been implicated in persistent neck and spinal pain, including psychological, social, and lifestyle factors. 
Table 3. Comparing upper quarter postural measures

\begin{tabular}{|c|c|c|c|c|c|c|c|c|c|c|c|}
\hline \multirow{2}{*}{$\begin{array}{l}\frac{y}{\frac{0}{0}} \\
\frac{\sqrt{0}}{\frac{\pi}{5}} \\
\frac{5}{>}\end{array}$} & \multirow[b]{2}{*}{ Time } & \multicolumn{2}{|c|}{ Mean $\pm S D$} & \multicolumn{4}{|c|}{ After Five Weeks } & \multicolumn{4}{|c|}{ After Eight Weeks } \\
\hline & & $\begin{array}{l}\text { Shortened- } \\
\text { length }\end{array}$ & $\begin{array}{l}\text { Through- } \\
\text { range }\end{array}$ & $\mathbf{F}$ & $\mathbf{P}$ & $\begin{array}{l}\text { Effect } \\
\text { Size }\end{array}$ & Power & $\mathbf{F}$ & $\mathbf{P}$ & $\begin{array}{l}\text { Effect } \\
\text { Size }\end{array}$ & Power \\
\hline \multirow{3}{*}{$\stackrel{5}{\mho}$} & Before the intervention & $45.80 \pm 4.10$ & $44.68 \pm 3.88$ & & & & & & & & \\
\hline & $\begin{array}{c}\text { Five weeks after the inter- } \\
\text { vention }\end{array}$ & $49.74 \pm 4.83$ & $46.92 \pm 4.16$ & 10.15 & $0.003^{\star}$ & 0.215 & 1.00 & 9.84 & $0.003^{\star}$ & 0.210 & 0.863 \\
\hline & $\begin{array}{l}\text { Eight weeks after the } \\
\text { intervention }\end{array}$ & $51.73 \pm 5.06$ & $48.59 \pm 4.48$ & & & & & & & & \\
\hline \multirow{3}{*}{ 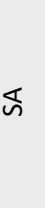 } & Before the intervention & $53.17 \pm 8.80$ & $51.48 \pm 8.06$ & & & & & & & & \\
\hline & $\begin{array}{l}\text { Five weeks after the inter- } \\
\text { vention }\end{array}$ & $57.05 \pm 7.64$ & $54.06 \pm 7.94$ & 3.32 & 0.077 & 0.082 & 0.426 & 0.322 & 0.081 & 0.080 & 0.416 \\
\hline & $\begin{array}{l}\text { Eight weeks after the } \\
\text { intervention }\end{array}$ & $59.57 \pm 7.36$ & $56.50 \pm 8.16$ & & & & & & & & \\
\hline \multirow{3}{*}{ 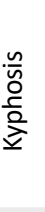 } & Before the intervention & $36.94 \pm 7.20$ & $37.05 \pm 7.21$ & & & & & & & & \\
\hline & $\begin{array}{c}\text { Five weeks after the inter- } \\
\text { vention }\end{array}$ & $34.52 \pm 7.27$ & $34.97 \pm 7.10$ & 0.203 & 0.655 & 0.005 & 0.072 & 0.176 & 0.678 & 0.005 & 0.069 \\
\hline & $\begin{array}{l}\text { Eight weeks after the } \\
\text { intervention }\end{array}$ & $32.42 \pm 7.61$ & $32.05 \pm 7.18$ & & & & & & & & \\
\hline \multirow{3}{*}{$\varangle$} & Before the intervention & $26.44 \pm 4.37$ & $23.99 \pm 6.44$ & & & & & & & & \\
\hline & $\begin{array}{l}\text { Five weeks after the inter- } \\
\text { vention }\end{array}$ & $23.90 \pm 4.07$ & $21.84 \pm 5.70$ & 0.013 & 0.910 & 0.001 & 0.051 & 0.570 & 0.455 & 0.015 & 0.114 \\
\hline & $\begin{array}{l}\text { Eight weeks after the } \\
\text { intervention }\end{array}$ & $21.07 \pm 4.57$ & $19.49 \pm 5.45$ & & & & & & & & \\
\hline
\end{tabular}

*Statistically significant differences were observed

CVA: Craniovertebral Angle; SA: Shoulder Angle; CA: Cranial Angle

This study deliberately included primary school male students with FHP, so the findings should not be generalized to all students with other postural changes. Further studies are required on other peoples with FHP or other postural changes, to clarify this problem more. Since movement mechanics differ between individuals with and without pain, the findings may not be generalizable to subjects who had FHP with neck pain or cervicogenic headache [38-40]. The study was limited to the eight weeks without follow up, so additional work with longer follow up better identifies the effect of training on the postural alignment.

\section{Conclusion}

Both through-range and shortened-length exercises altered upper quarter alignment, but the shortened-length training was slightly more effective for CVA. More studies are needed to investigate the effects of shortened-length training for other postural changes and to establish a relationship between posture and pain, and implications for rehabilitation.

\section{Compliance with ethical guidelines}

The study was approved by the Ethics Committee of research at the University of Allameh Tabataba'i, Department of Corrective Exercises and Sports Injuries.

Funding

The present paper was extracted from the MSc. thesis of the first author, Department of corrective exercises and sport injuries, Faculty of Sport Sciences, Allameh Tabataba'i University.

\section{Authors contributions}

Conceptualization, methodology, software, formal analysis, investigation, resources, data curation and writing - original draft preparation, project administration: All authors; Supervision: Rahman Sheikhhoseini.

\section{Conflict of interest}

The authors declared no conflict of interests.

\section{Ethical Considerations}




\section{References}

[1] Lee MY, Lee HY, Yong MS. Characteristics of cervical position sense in subjects with forward head posture. Journal of Physical Therapy Science. 2014; 26(11):1741-3. [DOI:10.1589/ jpts.26.1741] [PMID] [PMCID]

[2] Harrison BC, Hart JM. Reactive neuromuscular training in low-back pain rehabilitation: Part one. Athletic Training and Sports Health Care. 2010; 2(6):253-4. [DOI:10.3928/1942586420101229-02]

[3] Singla D, Veqar Z. Association between forward head, rounded shoulders, and increased thoracic kyphosis: A review of the literature. Journal of Chiropractic Medicine. 2017; 16(3):220-9. [DOI:10.1016/j.jcm.2017.03.004] [PMID] [PMCID]

[4] Panagiotopoulou G, Christoulas K, Papanckolaou A, Mandroukas $\mathrm{K}$. Classroom furniture dimensions and anthropometric measures in primary school. Applied Ergonomics. 2004; 35(2):121-8. [DOI:10.1016/j.apergo.2003.11.002] [PMID]

[5] Jeffries LJ, Milanese SF, Grimmer-Somers KA. Epidemiology of adolescent spinal pain: A systematic overview of the research literature. Spine. 2007; 32(23):2630-7. [DOI:10.1097/ BRS.0b013e318158d70b] [PMID]

[6] Ståhl M, Kautiainen H, El-Metwally A, Häkkinen A, Ylinen J, Salminen JJ, et al. Non-specific neck pain in schoolchildren: Prognosis and risk factors for occurrence and persistence. A 4-year follow-up study. Pain. 2008; 137(2):316-22. [DOI:10.1016/j.pain.2007.09.012] [PMID]

[7] Goodarzi F, Rahnama L, Karimi N, Baghi R, Jaberzadeh S. The effects of forward head posture on neck extensor muscle thickness: An ultrasonographic study. Journal of Manipulative and Physiological Therapeutics. 2018; 41(1):34-41. [DOI:10.1016/j.jmpt.2017.07.012] [PMID]

[8] Oliveira AC, Silva AG. Neck muscle endurance and head posture: A comparison between adolescents with and without neck pain. Manual Therapy. 2016; 22:62-7. [DOI:10.1016/j. math.2015.10.002] [PMID]

[9] Sabatucci A, Raffaeli F, Mastrovincenzo M, Luchetta A, Giannone A, Ciavarella D. Breathing pattern and head posture: Changes in craniocervical angles. Minerva Stomatologica. 2015; 64(2):59-74. [PMID]

[10] Kim MS, Cha YJ, Choi JD. Correlation between forward head posture, respiratory functions, and respiratory accessory muscles in young adults. Journal of Back and Musculoskeletal Rehabilitation. 2017; 30(4):711-5. [DOI:10.3233/BMR140253] [PMID]

[11] Shih HS, Chen SS, Cheng SC, Chang HW, Wu PR, Yang JS, et al. Effects of Kinesio taping and exercise on forward head posture. Journal of Back and Musculoskeletal Rehabilitation. 2017; 30(4):725-33. [DOI:10.3233/BMR-150346] [PMID]

[12] Gong W. The effects of cervical joint manipulation, based on passive motion analysis, on cervical lordosis, forward head posture, and cervical ROM in university students with abnormal posture of the cervical spine. Journal of Physical Therapy Science. 2015; 27(5):1609-11. [DOI:10.1589/jpts.27.1609] [PMID] [PMCID]

[13] Diab AA, Moustafa IM. The efficacy of forward head correction on nerve root function and pain in cervical spondylot- ic radiculopathy: A randomized trial. Clinical Rehabilitation 2011; 26(4):351-61. [DOI:10.1177/0269215511419536] [PMID]

[14] Cho J, Lee E, Lee S. Upper thoracic spine mobilization and mobility exercise versus upper cervical spine mobilization and stabilization exercise in individuals with forward head posture: A randomized clinical trial. BMC Musculoskeletal Disorders. 2017; 18:525. [DOI:10.1186/s12891-017-1889-2] [PMID] [PMCID]

[15] Ruivo RM, Pezarat-Correia P, Carita AI. Effects of a resistance and stretching training program on forward head and protracted shoulder posture in adolescents. Journal of Manipulative and Physiological Therapeutics. 2017; 40(1):1-10. [DOI:10.1016/j.jmpt.2016.10.005] [PMID]

[16] Seidi F, Rajabi R, Ebrahimi I, Alizadeh MH, Minoonejad H. The efficiency of corrective exercise interventions on thoracic hyper-kyphosis angle. Journal of Back and Musculoskeletal Rehabilitation. 2014; 27(1):7-16. [DOI:10.3233/BMR-130411] [PMID]

[17] Lee SM, Lee CH, O'Sullivan D, Jung JH, Park JJ. Clinical effectiveness of a Pilates treatment for forward head posture. Journal of Physical Therapy Science. 2016; 28(7):2009-13. [DOI:10.1589/jpts.28.2009] [PMID] [PMCID]

[18] Mulet M, Decker KL, Look JO, Lenton PA, Schiffman EL. A randomized clinical trial assessing the efficacy of adding $6 \times 6$ exercises to self-care for the treatment of masticatory myofascial pain. Journal of Orofacial Pain. 2007; 21(4):318-28. [PMID]

[19] Sheikhhoseini R, Shahrbanian Sh, Sayyadi P, O'Sullivan K. Effectiveness of therapeutic exercise on forward head posture: A systematic review and meta-analysis. Journal of Manipulative and Physiological Therapeutics. 2019; 41(6):530-9. [DOI:10.1016/j.jmpt.2018.02.002] [PMID]

[20] Lieber RL. Skeletal muscle structure, function \& plasticity: The physiological basis of rehabilitation. $3^{\text {rd }}$ ed. Philadelphia: Lippincott Williams \& Wilkins; 2009.

[21] Kendall FP, McCreary EK, Provance PG. Muscles: Testing and function with posture and pain. Philadelphia: Lippincott Williams \& Wilkins; 2005.

[22] Faul F, Erdfelder E, Lang AG, Buchner A. G*Power 3: A flexible statistical power analysis program for the social, behavioral, and biomedical sciences. Behavior Research Methods. 2007; 39(2):175-91. [DOI:10.3758/BF03193146] [PMID]

[23] Ruivo RM, Carita AI, Pezarat-Correia P. The effects of training and detraining after an 8 month resistance and stretching training program on forward head and protracted shoulder postures in adolescents: Randomised controlled study. Manual Therapy. 2016; 21:76-82. [DOI:10.1016/j.math.2015.05.001] [PMID]

[24] Diab AA. The role of forward head correction in management of adolescent idiopathic scoliotic patients: A randomized controlled trial. Clinical Rehabilitation. 2012; 26(12):1123-32. [DOI:10.1177/0269215512447085] [PMID]

[25] McRoberts LB, Cloud RM, Black CM. Evaluation of the New York posture rating chart for assessing changes in postural alignment in a garment study. Clothing and Textiles Research Journal. 2013; 31(2):81-96. [DOI:10.1177/0887302X13480558]

[26] Page P. Current concepts in muscle stretching for exercise and rehabilitation. International Journal of Sports Physical Therapy. 2012; 7(1):109-19. [PMID] [PMCID] 
[27] Brzycki M. Strength testing-predicting a one-rep max from reps-to-fatigue. Journal of Physical Education, Recreation \& Dance. 1993; 64(1):88-90. [DOI:10.1080/07303084.1993.10606 684]

[28] de Oliveira TS, Candotti CT, La Torre M, Pelinson PPT, Furlanetto TS, Kutchak FM, et al. Validity and reproducibility of the measurements obtained using the flexicurve instrument to evaluate the angles of thoracic and lumbar curvatures of the spine in the sagittal plane. Rehabilitation Research and Practice. 2012; 2012:186156. [DOI:10.1155/2012/186156] [PMID] [PMCID]

[29] Sullivan GM, Feinn R. Using effect size-or why the P value is not enough. Journal of Graduate Medical Education. 2012; 4(3):279-82. [DOI:10.4300/JGME-D-12-00156.1] [PMID] [PMCID]

[30] Shavandi N, Shahrjerdi Sh, Heidarpor R, Sheikh Hoseini R. [The effect of 7 weeks corrective exercise on thoracic kyphosis in hyper-kyphotic students (Persian)]. Journal of Shahrekord University of Medical Sciences. 2011; 13(4):42-50.

[31] Kim JY, Kwag KI. Clinical effects of deep cervical flexor muscle activation in patients with chronic neck pain. Journal of Physical Therapy Science. 2016; 28(1):269-73. [DOI:10.1589/ jpts.28.269] [PMID] [PMCID]

[32] Kong YS, Kim YM, Shim JM. The effect of modified cervical exercise on smartphone users with forward head posture. Journal of Physical Therapy Science. 2017; 29(2):328-31. [DOI:10.1589/jpts.29.328] [PMID] [PMCID]

[33] Clark M, Lucett S, Sutton BG, National Academy of Sports Medicine. NASM essentials of corrective exercise training. Burlington. MA: Jones \& Bartlett Learning; 2014.

[34] Sahrmann Sh. Movement system impairment syndromes of the extremities, cervical and thoracic spines. St. Louis: Mosby; 2010.

[35] Kisner C, Colby LA. Therapeutic exercise: Foundations and techniques. 6th ed. Philadelphia: F.A. Davis; 2012.

[36] Dobbins M, DeCorby K, Robeson P, Husson H, Tirilis D. School-based physical activity programs for promoting physical activity and fitness in children and adolescents aged 6-18. Cochrane Database of Systematic Reviews. 2009; (1):CD007651. [DOI:10.1002/14651858.CD007651]

[37] Janssen I, LeBlanc AG. Systematic review of the health benefits of physical activity and fitness in school-aged children and youth. International Journal of Behavioral Nutrition and Physical Activity. 2010; 7:40. [DOI:10.1186/1479-5868-7-40] [PMID] [PMCID]

[38] Hodges P, Smeets R. Interaction between pain, movement and physical activity: Short-term benefits, long-term consequences, and targets for treatment. The Clinical Journal of Pain. 2015;31(2):97-107. [DOI:10.1097/AJP.0000000000000098] [PMID]

[39] Sheikhhoseini R, Alizadeh MH, Salavati M, O'Sullivan K, Shirzad E, Movahed M. Altered lower limb kinematics during jumping among athletes with persistent low back pain. Annals of Applied Sport Science. 2018; 6(2):23-30. [DOI:10.29252/aassjournal.6.2.23]

[40] Sheikhhoseini R, O'Sullivan K, Alizadeh MH, Sadeghisani M. Altered motor control in athletes with low back pain: A literature review. Annals of Applied Sport Science. 2016; 4(4):43-50. [DOI:10.18869/acadpub.aassjournal.4.4.43] 